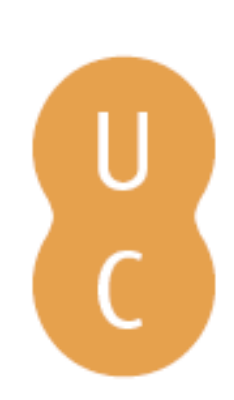

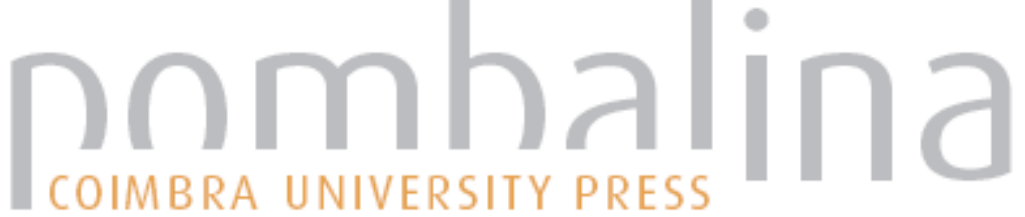

\section{As bibliotecas e a consolação da leitura}

Autor(es): $\quad$ Monteiro, João Gouveia

Publicado por: Imprensa da Universidade de Coimbra

URL

persistente: URI:http://hdl.handle.net/10316.2/36991

DOI: $\quad$ DOI:http://dx.doi.org/10.14195/978-989-26-1045-0_20

Accessed : $\quad$ 26-Apr-2023 11:12:43

A navegação consulta e descarregamento dos títulos inseridos nas Bibliotecas Digitais UC Digitalis, UC Pombalina e UC Impactum, pressupõem a aceitação plena e sem reservas dos Termos e Condições de Uso destas Bibliotecas Digitais, disponíveis em https://digitalis.uc.pt/pt-pt/termos.

Conforme exposto nos referidos Termos e Condições de Uso, o descarregamento de títulos de acesso restrito requer uma licença válida de autorização devendo o utilizador aceder ao(s) documento(s) a partir de um endereço de IP da instituição detentora da supramencionada licença.

Ao utilizador é apenas permitido o descarregamento para uso pessoal, pelo que o emprego do(s) título(s) descarregado(s) para outro fim, designadamente comercial, carece de autorização do respetivo autor ou editor da obra.

Na medida em que todas as obras da UC Digitalis se encontram protegidas pelo Código do Direito de Autor e Direitos Conexos e demais legislação aplicável, toda a cópia, parcial ou total, deste documento, nos casos em que é legalmente admitida, deverá conter ou fazer-se acompanhar por este aviso.

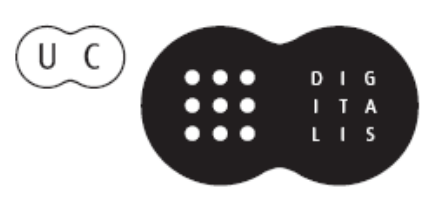



Tendo como pano de fundo as Comemorações dos seus 500 anos, a Biblioteca Geral da Universidade de Coimbra organizou um Congresso Internacional subordinado ao tema "A Biblioteca da Universidade: permanência e metamorfoses", que teve lugar nos dias 16, 17 e 18 de janeiro de 2014, no auditório da Reitoria da Universidade de Coimbra.

O objetivo maior desta reunião científica foi o de refletir sobre o presente e o futuro das bibliotecas que servem públicos universitários. Numa outra vertente, procurou chamar-se a atenção para a importância de que a Biblioteca se reveste, tendo em vista o progresso do conhecimento técnico e científico. Por último, o Congresso pretendeu instituir-se como oportunidade de reflexão prospetiva e como lugar de encontro entre as sensibilidades de todos os que trabalham profissionalmente com livros e com outros suportes de natureza bibliográfica.

Nesse sentido, foram apresentadas Conferências, Mesas Redondas e sessões de Testemunhos em torno de temas como o valor das bibliotecas universitárias, a biblioteca universitária em contexto; as mudanças e os desafios; a biblioteca universitária e a sociedade da informação e conhecimento; o impacto do acesso aberto na comunidade científica, e as bibliotecas digitais. 


\section{AS BIBLIOTECAS E A CONSOLAÇÃO DA LEITURA}

Começo por vos prevenir de que só aqui estou devido à inexcedível gentileza do Prof. José Cardoso Bernardes, ilustre Diretor da nossa vetusta Biblioteca Geral e a quem aproveito para felicitar, não só por esta realização, mas também por todo o trabalho, dedicação e competência que tem demonstrado, num período tão difícil e em circunstâncias tão adversas, à frente daquela que é, sem dúvida, a jóia de Coroa da nossa Universidade.

Com efeito, reconhecendo a tremenda importância prática e simbólica que uma boa biblioteca tem para qualquer investigador, devo confessar que eu não sou aquilo a que se costuma chamar "um rato de biblioteca"... Por circunstâncias diversas, que resultam da minha própria especialização profissional (na área da história militar antiga e medieval europeias), tenho muito mais experiência de trabalho de arquivo, de campo e de gabinete, do que propriamente 'vida de biblioteca'. Pode, todavia, ser que este perfil, associado a uma grande paixão pelos livros e pela leitura, bastem para não cometer a deselegância de recusar o convite amável e insistente de um excelente amigo para partilhar convosco algumas reflexões.

É claro que, em momentos diversos da minha carreira, e de forma mais ou menos pontual, trabalhei em bibliotecas ilustres. Posso dizer-vos que a recordação mais intensa que tenho dessa experiência decorre das semanas que vivi dentro da British Library, em Londres, no início dos anos noventa. Eu precisava de estudar o célebre De Regimine Principum de Egídio Romano (ou Frei Gil de Roma), um 'espelho de príncipes' escrito por volta de 1285 para o futuro rei capetíngio Filipe IV, "o Belo", de quem o autor era o dedicado mestre. Como geralmente acontece na literatura medieval, a obra encontra-se dividida em três Partes (ou livros), 
cada qual com o seu tema e subdividido também em três partes (boa retórica oblige). Eu desconfiava que a terceira parte do terceiro livro de Gil de Roma, dedicada à preparação da guerra e da qual conhecia citações pontuais em vários escritos portugueses dos finais da Idade Média, não seria mais do que uma reprodução de longos trechos da Epitoma Rei Militaris de Flávio Vegécio Renato, o mais importante tratadista militar latino. Vegécio escreveu por volta do ano 400 d. C., mas a sua obra tornou-se um verdadeiro best seller durante todo o milénio seguinte e influenciou decisivamente a cultura medieval europeia. Dela sobreviveram mais de 300 manuscritos latinos e traduções para, pelo menos, sete línguas diferentes. Quase um recorde entre os autores latinos, um valor só superado por Cícero, Ovídio, e Vergílioº ${ }^{1}$

Esperei ansiosamente na sala da Northern Library (onde a British Library concentrava muitos dos seus melhores 'reservados') que me trouxessem a tradução castelhana de Egídio Romano, preparada em meados do século XIV por Frei Juan García de Castrojeríz (confessor da rainha D. Maria) e impressa em Sevilha em 1494! Ouviram bem, estamos a falar de um precioso incunábulo, designação atribuída às primeiras obras impressas com tipos móveis ainda em registo de imitação dos antigos manuscritos. A sensação foi muito intensa naquelas tardes em que consultei o manuscrito, de que ainda hoje conservo com imenso carinho uma fotocópia encadernada do respetivo microfilme. Além disso, a minha hipótese ficou amplamente confirmada, pois Gil de Roma, naqueles vinte e poucos capítulos da sua obra, praticamente limita-se a reproduzir (resumindo-os e simplificando-os) os principais ensinamentos militares de Vegécio (sem o citar, é claro, tanto mais que a noção moderna de plágio não existia ainda na cultura medieval europeia ${ }^{2}$ ). Lembrado da afirmação do cro-

1 Monteiro, João Gouveia; Braga, José Eduardo - Vegécio. Compêndio da Arte Militar. Ed. bilingue (latim-português). Coimbra: Imprensa da Universidade, 2009.

2 Hoje, a noção de plágio está institucionalizada, mas não deixa de ser divertido recordar uma passagem do extraordinário livro do romancista israelita Amos Oz: "O meu pai costumava dizer: copiar as ideias de um livro é muito feio, é considerado plágio, roubo literário. Mas se as copiarmos de dez livros, chamam-nos investigadores, e se for de trinta ou quarenta livros somos investigadores notáveis" (OZ, Amos - Uma história de amor e trevas. Lisboa: Asa, 2007. p. 162). 
nista Gomes Eanes de Zurara, segundo a qual D. João I mandava muitas vezes ler na sua "câmara" trechos do De Regimine Principum (certamente da tradução castelhana, que aliás existia na biblioteca do seu filho D. Duarte, por isso a desejei consultar), fiquei seguro do bom conhecimento de pelo menos parte da Epitoma Rei Militaris em Portugal na primeira metade do século XV, ainda que a tradução que Rui de Pina atribui ao infante D Pedro, duque de Coimbra, possa nunca ter chegado a ver a luz do dia (e eu até sou daqueles que acreditam que ela existiu realmente, mas entretanto se perdeu).

E já que falei na livraria de D. Duarte (composta por cerca de oitenta e quatro códices, dos quais vinte em latim e 64 "em linguagem"), deixem-me dizer-vos que uma tarefa que sempre me encantou foi a de estudar a composição das bibliotecas de personagens históricas. Diz-me o que lês, dir-te-ei quem és... Neste género de 'voyeurismo intelectual', aprende-se imenso sobre as representações do mundo que enformam as figuras que estudamos, e o caso da biblioteca de D. Duarte (rei entre 1433 e 1438) é especialmente interessante, não só pelo volume de códices ali representado (à escala da sua época e tendo em conta a circunstância de se tratar de uma biblioteca laica), como também pela sua diversidade (crónicas, histórias de heróis da Antiguidade, livros de religião, de filosofia, de medicina e de direito, romances de cavalaria, tratados de direito bélico, obras sobre astrologia, sobre caça e sobre gineta, etc.) e até pela particularidade de vários títulos estarem repetidos, surgindo uma vez em latim e outra em tradução para "língua vulgar" (castelhano ou catalão, nomeadamente).

A respeito da importância do estudo da composição das bibliotecas, gostaria de propor nesta cerimónia comemorativa dos 500 anos da BGUC que se aprofundasse o estudo da coleção da extraordinária Biblioteca Joanina. Seria a melhor homenagem que poderíamos prestar a um espaço que foi decisivo (posso assegurá-lo pelo meu testemunho direto) no lançamento da candidatura da Universidade de Coimbra a Património Mundial da Humanidade (designadamente no que diz respeito à inscrição da UC na chamada 'lista indicativa' da Comissão Nacional da UNESCO, 
à época - e estamos a falar do ano de 2004 - presidida pelo Dr. José Sasportes). Fica aqui a sugestão.

Continuando a voar sobre o fil rouge da paixão de grandes figuras históricas pelos livros e pelas bibliotecas, não posso deixar de evocar aqui a fundação de Alexandria pelo mais célebre discípulo de Aristóteles, Alexandre Magno, o maior general da história do mundo antigo, que passa por ter trazido sempre consigo um exemplar da Ilíada de Homero. A história é verosímil, tanto mais que está provado que em 334 a. C., à partida para a sua longa campanha de conquista do mundo persa (campanha que o conduziria até à cordilheira do Hindu Kush, no atual Afeganistão, e às margens do rio Indo, ou seja, para além dos limites do mundo conhecido pelos Gregos de então), Alexandre incluiu na sua comitiva botânicos, geógrafos, exploradores vários e até um historiador, chamado Calístenes e sobrinho do seu mestre Aristóteles.

Mas também Júlio César, três séculos mais tarde, compreendia a importância da função das bibliotecas e terá delineado com o prolífico letrado romano Marco Terêncio Varrão a construção da primeira biblioteca pública de Roma, um projeto que, décadas mais tarde, viria a ser concretizado por Asínio Polião. Não deixa de ser curiosa esta atenção do conquistador das Gálias à cultura e aos livros, pois era também com base em argumentos intelectuais que os seus mais tenazes adversários políticos se opunham, em nome da defesa dos velhos ideais republicanos, à ditadura de César: evoque-se apenas o suicídio de Catão em África, após a derrota averbada na batalha de Tapso, em 46 a. C.; segundo consta, Catão pôs termo à sua vida enquanto lia uma passagem do Fédon de Platão sobre a imortalidade da alma...

Pelos vistos, na Roma antiga, o gosto pelos livros era comum aos ditadores, uma vez que, quatro décadas antes de César, já Lúcio Cornélio Sula havia feito questão de incluir no tremendo saque que fizera na Ásia e na Grécia a famosa biblioteca de Appelicon, da qual faziam parte, não só uma antiquíssima cópia da Ilíada, mas também obras de Aristóteles e de Teofrasto que se revelariam essenciais para a difusão das doutrinas peripatéticas em Roma. 
A importância do saber era, não há dúvida, reconhecida pelos antigos. O que teria sido de Sócrates, de Séneca ou de Boécio sem a 'consolação da filosofia', por exemplo?... Recorde-se também o que escreveu, nas Disputas Tusculanas, Marco Túlio Cícero, provavelmente o maior prosador latino (e um autor bem representado na livraria do nosso rei D. Duarte e traduzido pelo regente D. Pedro, duque de Coimbra): "Não existe ocupação tão agradável como o saber; o saber é o meio de nos dar a conhecer, ainda neste mundo, o infinito da matéria, a imensa grandeza da Natureza, os céus, as terras e os mares. O saber ensinou-nos a piedade, a moderação, a grandeza do coração; tira-nos as nossas almas das trevas e mostra-nos todas as coisas, o alto e o baixo, o primeiro, o último e tudo aquilo que se encontra no meio; o saber dá-nos os meios de viver bem e felizmente; ensina-nos a passar as nossas vidas sem descontentamentos e sem vexames" 3 .

Gosto de pensar o problema da importância das bibliotecas, dos livros e do saber também numa perspetiva de diálogo cultural e inter-religioso. Na verdade, as três grandes religiões abraâmicas (Judaísmo, Cristianismo e Islão) são também as três 'religiões do livro', e isso desde logo evoca algo que é muito querido à Universidade de Coimbra, à sua tradição medieval e à matriz ecuménica da velha urbe mondeguina, tão bem traduzida na sua importante comunidade moçárabe do século XI. De facto, se o livro é fonte de conhecimento, o conhecimento é essencial para a compreensão do outro, e a compreensão do outro é uma condição sine qua non do diálogo imprescindível para a construção da paz entre homens de todas as etnias, de todas as culturas, de todas as religiões e de todos os níveis de desenvolvimento económico e tecnológico. Nos seus Ensaios, escritos em meados do século XVI, Michel de Montaigne (1533-1592) recorda a conquista do Novo Mundo pelos Espanhóis, lembra que, em menos do meio século, a população dessa região do globo caiu de perto de oitenta para apenas dez milhões, e evoca a chacina dos Aztecas e dos Incas pelos homens de Hernán Cortés e de Francisco

3 Cícero, Marco Túlio - Disputas Tusculanas. Ed. bilingue (latim-espanhol). Cidade do México: Universidad Nacional Autonoma De Mexico, 2009. 
Pizarro, convencidos de que sabiam o que era um ser humano 'normal': "Não conseguíamos entender uma palavra da sua língua; os seus modos e até mesmo o seu aspeto e roupas eram muito diferentes dos nossos. Qual de nós é que não os tomaria por brutos e selvagens? Qual de nós é que não atribuiria o seu silêncio a estupidez e bruta ignorância? Afinal de contas, eles desconheciam o nosso beija-mão e as nossas profundas e complexas vénias" 4 .

Desta tribuna saúdo, pois, a iniciativa da Reitoria da Universidade de Coimbra de criação de um Centro Multiculto, assinalando as comemorações do início do governo de D. Sesnando, o alvazil moçárabe a quem Fernando I "o Magno" entregou o controlo dos campos de Coimbra (e não só) após a reconquista cristã da nossa cidade, em 1064. Essa postura de fomento do diálogo de civilizações, pela qual há tantos anos me bato, só pode enobrecer a nossa instituição e a nossa cidade. Ela é digna da memória dos grandes centros de tradução de obras relevantes da Antiguidade (gregas, latinas e árabes) instalados durante a Idade Média em cidades multiculturais como Palermo ou Toledo, graças aos quais se difundiram (e se salvaram!) muitas das mais preciosas obras que a mão humana compôs, mau grado o alarme daqueles que - como no caso do bibliotecário do romance de Umberto Eco, O Nome da Rosa $a^{5}$ temiam o debate de ideias, a renovação do saber e a ressurreição do riso como expressão do intrinsecamente humano.

Deixem-me acrescentar, neste ponto, que tenho uma enorme apreensão relativamente aos atuais níveis de leitura convencional por parte dos nossos jovens. É preciso apostarmos muito forte em ações de sensibilização para a importância dos livros e da leitura entre aqueles que serão os nossos cidadãos, os nossos professores, os nossos governantes de amanhã. Como explicou um dia Harold Bloom (doutor honoris causa por esta universidade) a internet e os jornais dão-lhes muita informação, mas só o livro (seja no formato tradicional, seja em e-book ou outro qualquer)

\footnotetext{
${ }^{4}$ Apud BotTon, Alain de - O consolo da filosofia. 5. ${ }^{a}$ ed. Lisboa: Publicações D. Quixote, 2001. p. 167.

5 ECO, Umberto - O nome da Rosa. Lisboa: Editora Difel, 2004.
} 
lhes garante a sabedoria a que eles têm direito para viverem plenamente a sua vida intelectual. Os nossos jovens precisam de se emocionar diante das grandes criações artísticas, literárias e musicais da Humanidade! E nós temos de os ajudar, motivar, despertar para que tal aconteça. Vejo com muita apreensão as dificuldades que diversas secções culturais e organismos autónomos da Associação Académica de Coimbra (ligados à música, ao teatro, à dança, à leitura) atravessam hoje por falta de apoios e de membros, e não raro me assusto quando descubro que, na minha sala de aula, menos de $10 \%$ dos presentes desenvolve alguma atividade cultural (ou até desportiva ou social) com caráter de regularidade. Haja imaginação para (por exemplo, em torno de grandes livros, ou de grandes filmes), inverter esta situação e rasgar os horizontes dos nossos jovens, permitindo-lhes passar a ver a cores aquilo que tantos deles, atualmente, veem apenas a preto e branco.

Claro que os livros não são a única fonte de conhecimento e de sabedoria. Montaigne também nos alertou para isso. Os livros não se pronunciam sobre muitas matérias e as nossas experiências extraliterárias também são essenciais ao conhecimento pleno da vida e à compreensão aberta e arejada do mundo. Vejamos a história e a cultura servindo-nos da imagem de um palimpsesto, esse manuscrito que se pode sempre rasurar e escrever de novo. Saibamos servir-nos das bibliotecas não como ponto de chegada, mas sim como ponto de partida e motor de arranque do nosso crescimento intelectual, ético e humano, com o mesmo espírito disponível para a mudança e a autotransformação que o filósofo francês de origem lituana Emmanuel Lévinas, falecido em 1995, atribui a Abraão, quando o compara com Ulisses. Aqui o recordo, para finalizar, servindo-me da versão portuguesa do meu sábio amigo Anselmo Borges:

"Ulisses, depois da guerra de Troia, de volta a casa, vive a aventura de encontros múltiplos com outros, experiências variadas. Travou combates, enfrentou obstáculos sem fim, conheceu o diferente. Coberto de vitórias e glória, regressa. Mas chegado a casa, mesmo disfarçado, 'diferente' do Ulisses que partira, é ainda o 'mesmo', que o seu cão, pelo faro, e Penélope, pelo amor, reconhecem. Ulisses representa o herói do regresso, 
que contactou com o diferente apenas para, num mundo domesticado e assimilado, reduzi-lo ao mesmo.

Abraão, pelo contrário, ouviu uma voz que o chamava e partiu da sua terra, para nunca mais voltar. A sua viagem vai na direção do novo, do não familiar, do diferente, do Outro. Ninguém o espera num regresso ao ponto de partida. Há só uma palavra de promessa que o chama para um futuro sempre mais adiante. Abraão ouve, caminha, transcende. A sua identidade transfigura-se a cada passo, é processual, histórica. Rompe com o passado, e o seu êxodo vai no sentido de um futuro imprevisível e novo"6 ...

\section{Referências bibliográficas}

BORGES, Anselmo - Religião e Diálogo Inter-Religioso. Coimbra: Imprensa da Universidade, 2010.

BOTTON, Alain de - O consolo da filosofia. $5 .^{\mathrm{a}}$ ed. Lisboa: Publicações D. Quixote, 2001.

CíCERO, Marco Túlio - Disputas Tusculanas. Ed. bilingue (latim-espanhol). Cidade do México: Universidad Nacional Autonoma De Mexico, 2009.

ECO, Umberto - O nome da Rosa. Lisboa: Editora Difel, 2004.

MonteIro, João Gouveia; BRAGA, José Eduardo - Vegécio. Compêndio da Arte Militar. Ed. bilingue (latim-português). Coimbra: Imprensa da Universidade, 2009. OZ, Amos - Uma história de amor e trevas. Lisboa: Asa, 2007.

${ }^{6}$ BORges, Anselmo - Religião e Diálogo Inter-Religioso. Coimbra: Imprensa da Universidade, 2010. pp. 132-133. 
José Augusto Cardoso Bernardes é Professor da Faculdade de Letras da Universidade de Coimbra e Diretor da Biblioteca Geral da Universidade

Ana Maria Eva Miguéis é coordenadora do Serviço Integrado das Bibliotecas da Universidade de Coimbra

Carla Ferreira é bibliotecária nos Serviços de Biblioteca e Documentação da Faculdade de Letras da Universidade de Coimbra. 


\section{Série Documentos}

Imprensa da Universidade de Coimbra

Coimbra University Press

2015

C •

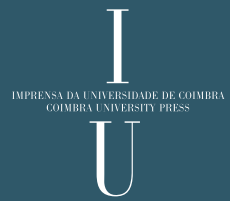

